\title{
Research on Spatial Pattern and Its Industrial Distribution of Commercial Space in Mianyang Based on POI Data
}

\author{
Da Zheng, Changqi Li \\ Southwest University of Science and Technology, Mianyang, China \\ Email: zdswust@163.com
}

How to cite this paper: Zheng, D. and $\mathrm{Li}$, C.Q. (2020) Research on Spatial Pattern and Its Industrial Distribution of Commercial Space in Mianyang Based on POI Data. Journal of Data Analysis and Information Processing, 8, 20-40.

https://doi.org/10.4236/jdaip.2020.81002

Received: December 20, 2019

Accepted: January 11, 2020

Published: January 14, 2020

Copyright $\odot 2020$ by author(s) and Scientific Research Publishing Inc. This work is licensed under the Creative Commons Attribution International License (CC BY 4.0)

http://creativecommons.org/licenses/by/4.0/

\begin{abstract}
The rational layout of urban commercial space is conducive to optimizing the allocation of commercial resources in the urban interior space. Based on the commercial POI (Point of Interest) data in the central district of Mianyang, the characteristics of urban commercial spatial pattern under different scales are analyzed by using Kernel Density Estimation, Getis-Ord $G_{i}^{*}$, Ripley's K Function and Location Entropy method, and the spatial agglomeration characteristics of various industries in urban commerce are studied. The results show that: 1) The spatial distribution characteristics of commercial outlets in downtown Mianyang are remarkable, and show a multi-center distribution pattern. The hot area distribution of commercial outlets based on road grid unit is generally consistent with the identified commercial density center distribution. 2) The commercial grade scale structure has been formed in the central urban area as a whole, and the distribution of commercial network hot spots based on road grid unit is generally consistent with the identified commercial density center distribution. 3) From the perspective of commercial industry, the differentiation of urban commercial space "center-periphery" is obvious, and different industries show different spatial agglomeration modes. 4) The multi-scale spatial agglomeration of each industry is different, the spatial scale of location choice of comprehensive retail, household appliances and other industries is larger, and the scale of location choice of textile, clothing, culture and sports is small. 5) There are significant differences in specialized functional areas from the perspective of industry. Mature areas show multi-functional elements, multi-advantage industry agglomeration characteristics, and a small number of developing areas also show multi-advantage industry agglomeration characteristics.
\end{abstract}

\section{Keywords}

Point of Interest (POI), Commercial Space, Aggregating Feature, Industry 
Distribution, Mianyang

\section{Introduction}

The spatial layout of the commercial space has been a hot spot in modern urban research; the western scholars have paid close attention to the commercial space theory such as the Central Place Theory [1] [2], the Reilly's Law of Retail Gravitation [3], the theory of spatial utilization structure [4] [5] etc., which have become the important theoretical basis of the commercial space layout and the commercial siting, so as to reveal the spatial law of the relationship between the scale, level, location, traffic and the function of the business district. The researches focus on the distribution characteristics of business space, the grade of business scale, the internationalization of retail industry, the reconstruction of business space and the choice of consumer behavior. The domestic research on the layout of commercial space has been dominated by qualitative analysis of spatial characteristics in the 1980s. With the arrival of the wave of globalization and the development of new economy in the new century, great changes have taken place in urban commercial space, and all kinds of new business forms have appeared. As a result, the research on commercial space in emerging cities has gradually enriched. Increasingly, scholars study the structure of urban commercial space layout by investigating consumer shopping trips and travel and residents' consumption behavior [6] [7] [8] [9], however, the traditional research is limited to data and technology, and lacks the analysis of the overall pattern of urban commerce and the characteristics of local spatial differentiation based on large samples. With the rise of large data, the new technology methods and means provide the possibility for the research of urban commercial space structure. For example, Zhou Suhong et al. [10] used GPS data to explore the attractive attenuation effect of commercial space. Wang De et al. [11] made a comparison of different business districts in Shanghai by using cell phone signaling data. Hu Qingwu et al. [12] used Weibo check-in data to study the urban business districts.

In recent years, based on POI big data, the empirical study of space has emerged to identify urban hot spots based on KDE (Kernel Density Estimation), Moran's I, Getis-Ord $G_{i}^{*}$ etc. For example, Chen Weishan et al. [13] identified the characteristics of hot spots in Guangzhou retail industry based on POI data, and the relationship between the spatial agglomeration characteristics of different retail formats and its market and positioning, business model and location strategy is discussed. Xu Dong et al. [14] analyzed the distribution pattern of the urban leisure tourism space based on the POI data, and drew the conclusion that the leisure tourism space has obvious dependence on the scale. Zhao Hongbo et al. [15] took cultural facilities as the research object, quantitatively analyzed the evolution of the spatial pattern of Zhengzhou cultural facilities and its location 
layout, and discussed the development direction of Zhengzhou cultural facilities. It can be seen that the quantitative research of spatial characteristics based on poi big data has become a new trend. Based on the POI data of the central district of Mianyang and the method of spatial data analysis, this paper further studies the industry distribution and agglomeration characteristics of urban commercial space from the perspective of commercial form on the basis of identifying the urban commercial center and analyzing the characteristics of urban commercial spatial pattern. From the perspective of research, we pay attention to the influence of industry attributes on the location choice of commercial outlets, and make up for the shortcomings of the previous research from the perspective of the past. In the research data, we obtain the latest POI geographical space big data, overcome the shortcomings of the traditional "small data" acquisition difficulty, low precision and so on. On the research scale, we realize the combination of multi-scale spatial units such as municipal district, street, road grid and so on. On the whole, the research is helpful to expand the research content of urban commercial space at the micro level, and can provide scientific reference for the adjustment of urban industrial structure and the optimization of commercial space in Mianyang.

\section{Data Sources and Research Methods}

\subsection{Study Area and Data Sources}

The central district of Mianyang is selected as the study area, with a total area of about 488.7 square kilometers. Mianyang is surrounded by four mountains: Xishan Mountain, Fulei Mountain, Nanshan Mountain and Snake Mountain. The city is located in mountainous region. Fujiang River is from northeast to southwest, Furong River is from east to west, Anchang River passes through the city from west to east, forming the landscape pattern of the intersection of three rivers and four mountains, and the city presents a typical group layout form because of the mountains and water. With the central area as the core, Youxian area is located in the East, Gaoshui, Qingyi area North, Yuanyi and high-tech area West, Tangxin, Xiaojian and Songya area south. In the process of ChengDe-Mian economic belt integration, Mianyang will share some of the central functions, become the northern sub-center of Chengdu Metropolitan Economic Zone, and will also become the center of the traditional trade circulation in northwest Sichuan. Mianyang will share some of the central functions, becoming the northern sub-centre of the Chengdu Metropolitan Economic Zone and a traditional hub for commerce and trade in the Northwest Sichuan. In recent years, due to the changes in the urban population structure and the increase in the average living consumption level of residents, the new commercial centers such as Kaide, Wanda, Changhong, Parkson and Meixi Shopping Centers have developed rapidly, and the average annual growth rate of the total retail sales of consumer goods has reached more than 14\% (Figure 1). But along with the development of commerce, But with the development of commerce, there are still 


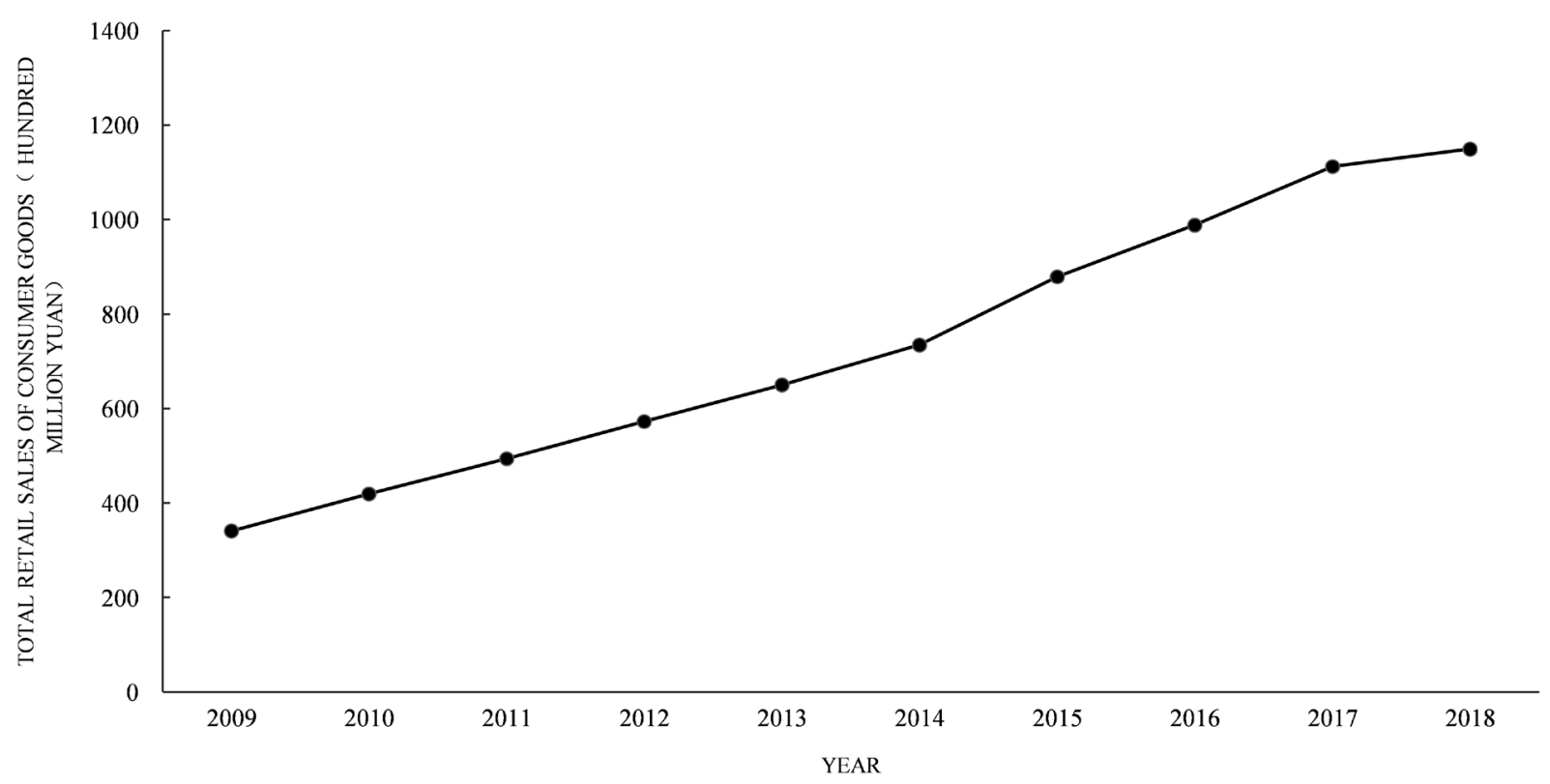

Figure 1. Total retail sales of consumer goods in Mianyang from 2009 to 2018.

some problems such as uneven spatial distribution and the over-homogeneity of different business forms. Therefore, this study can provide a typical case for the study of the commercial space layout and its agglomeration characteristics of the sub-central city of the metropolitan economic zone.

The poi data is mainly obtained from Gaode Map's open platform, and the data acquisition time is May 2019. The data include 21 types of data, such as catering, shopping, life services, entertainment and leisure, health care, institutional groups, companies, cars, real estate and so on. Compared with the traditional survey data, the detailed type classification of poi data makes it possible to study the business space from the perspective of the industry. Based on the classification of National Economy Industry Classification Standard ${ }^{1}$, this paper mainly selects several subcategories of retail industry, catering industry and entertainment industry to analyze, and reclassifies the subcategories with vague industry characteristics, such as "shopping related places" and "specialty stores". After spatial matching, deduplication, and deletion of low-recognized commercial outlets, a total of 30,979 valid POI data were obtained (Table 1).

The spatial distribution of commercial outlets in the study area is shown in Figure 1. Ensure that the POI data is consistent with the geographic coordinate system of the administrative division data of Mianyang, and converting them into projections.

${ }^{1}$ The National Economic Industry Classification Standard (GB/T 4754-2017) states that the retail industry refers to the sales activities of department stores, supermarkets, specialized retail stores, brand stores, and stalls that are mainly targeted at end consumers (such as residents) Sales activities by Internet, post, telephone, vending machines, etc. According to statistical standards, it includes 9 types of retail industries, including comprehensive retail, retail of food, beverages and tobacco products, retail of textiles, clothing and daily necessities, cultural, sports products and equipment. Due to data limitations, this article mainly focuses on retail establishments with fixed stores, and does not consider stalls, no stores, and other retail industries. 
Table 1. Industry categories of commercial POI data in Mianyang downtown.

\begin{tabular}{|c|c|c|c|}
\hline Industry Category & POI Subcategory & Quantity & Proportion (\%) \\
\hline Comprehensive Retail & Convenience stores, shopping malls, supermarkets, comprehensive markets & 2591 & 8.36 \\
\hline $\begin{array}{l}\text { Food, beverage and tobacco } \\
\text { products }\end{array}$ & $\begin{array}{l}\text { Tobacco and liquor stores, agricultural and sideline products markets, fruit } \\
\text { markets, vegetable markets, seafood markets }\end{array}$ & 2059 & 6.65 \\
\hline Textiles, clothing and daily necessities & Cosmetics store, gift shop, clock shop, glasses shop, flower market, bicycle store & 4093 & 13.21 \\
\hline $\begin{array}{l}\text { Cultural, sporting goods and } \\
\text { equipment }\end{array}$ & $\begin{array}{l}\text { Sporting goods store, stationery store, book store, antique calligraphy and } \\
\text { painting market, jewelry store, audio-visual store }\end{array}$ & 703 & 2.27 \\
\hline Medicine and medical equipment & Pharmacies, clinics, health care outlets & 2118 & 6.84 \\
\hline $\begin{array}{l}\text { Automobile, motorcycle fuel and } \\
\text { spare parts }\end{array}$ & $\begin{array}{l}\text { Motorcycle and accessories sales, automotive and spare parts sales, used car } \\
\text { trading market }\end{array}$ & 898 & 2.9 \\
\hline $\begin{array}{l}\text { Household appliance and electronic } \\
\text { product }\end{array}$ & $\begin{array}{l}\text { Home appliance stores, mobile phone sales, digital electronics, comprehensive } \\
\text { home appliance stores }\end{array}$ & 1155 & 3.73 \\
\hline $\begin{array}{l}\text { Hardware, home and interior } \\
\text { decoration materials }\end{array}$ & $\begin{array}{l}\text { Fabric market, Kitchen and bathroom furniture market, lamp porcelain market, } \\
\text { furniture city, building materials and hardware market }\end{array}$ & 5454 & 17.61 \\
\hline Leisure and recreation & Entertainment, leisure, movie theater & 1099 & 3.55 \\
\hline Catering service & $\begin{array}{l}\text { Cake shop, cafe, fast food restaurant, cold drink restaurant, restaurant, dessert } \\
\text { shop }\end{array}$ & 10809 & 34.89 \\
\hline
\end{tabular}

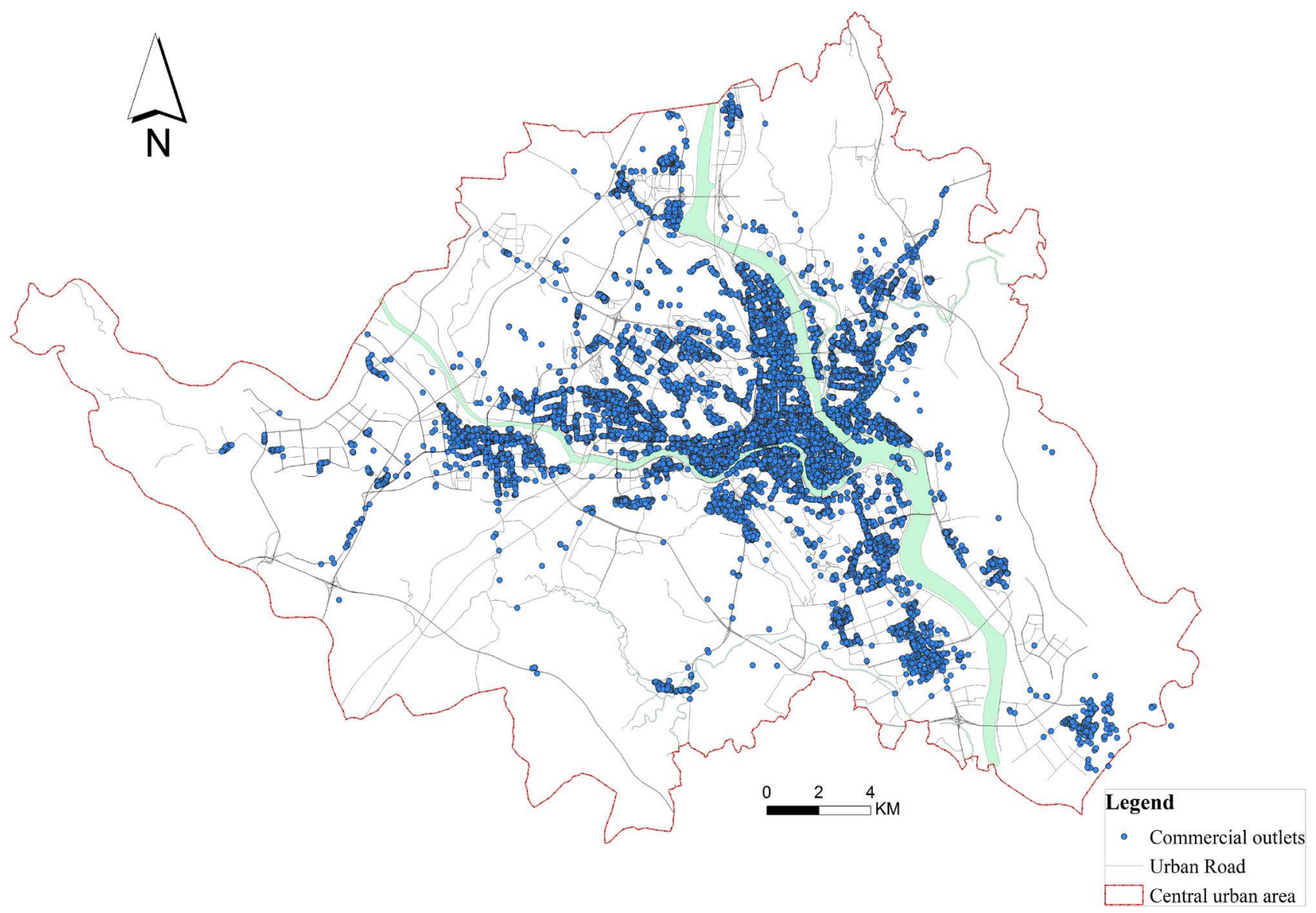

Figure 2. Spatial distribution of commercial POI in central district of Mianyang. 


\subsection{Research Methods}

\subsubsection{Kernel Density Estimation}

The kernel density estimation method is used to calculate the density of the point features around each output raster cell. The points closer to the center have greater weight.

$$
f_{n}(d)=\frac{1}{h^{2}} \sum_{i=1}^{n} k\left(\frac{d-d_{i}}{h}\right)
$$

where $h$ is the threshold radius, that is broadband, $n$ represents the number of sample points, $d-d_{i}$ is the distance from the estimated point to the sample point, $k$ is equal to the spatial weight function.

\subsubsection{Getis-Ord $G_{i}^{*}$}

The statistic is used to analyze the agglomeration degree of attribute values at the local spatial level by comparing the local summation of adjacent elements with the summation of all elements in a given distance range. The formula is expressed as follows:

$$
G_{i}^{*}=\frac{\sum_{j=1}^{n} W_{i j}(d) X_{j}}{\sum_{j=1}^{n} X_{j}}
$$

In the formula: $x_{j}$ is the element attribute value of the $j$ spatial unit; $n$ is the total number of elements; $w_{i j}$ represents the spatial weight matrix. If the distance between the $i$ and the $j$ spatial units is within a given critical distance $d$, they are considered to be neighbors and the elements in the spatial weight matrix are 1 , otherwise, the element is 0 .

$$
\delta_{j}=\frac{m_{j}}{p_{j}}
$$

where $\delta_{j}$ is the density index of commercial outlets in the $j$-th block unit, $m_{j}$ is the number of commercial outlets in the block, $p_{j}$ is the area of the $j$-th block.

\subsubsection{Ripley's K Function}

Ripley's K function can be used to analyze the distribution patterns of spatial point features on different spatial scales. The calculation formula is as follows:

$$
K(d)=A \sum_{i=1}^{n} \sum_{j=1}^{n} \frac{w_{i j}(d)}{n^{2}}
$$

In the formula: $A$ is the area under study; $n$ is the number of commercial outlets in each industry; $d$ is the distance threshold; $w_{i j}(d)$ is the distance between commercial outlets $i$ and $j$ in a certain industry within the range of $d$. In 1977, Besag proposed to replace $K(d)$ with $L(d)$ and to square $K(d)$ with a linear transformation to keep the variance stable. The formula is:

$$
L(d)=\sqrt{\frac{K(d)}{\pi}}-d
$$


The relationship between $L(d)$ and $d$ can test the spatial distribution pattern of various industries within the range of distance $d . L(d)=0$ means that the industry is randomly distributed, $L(d)>0$ means that the industry is agglomerated, $L(d)<0$ means that the industry is decentralized.

\subsubsection{Location Quotient}

Location Quotient is often used to analyze the degree of specialization of regional leading industries, which is helpful to measure the spatial distribution of a certain factor. This study uses location entropy indicators to analyze the degree of regional specialization of the retail industry. The higher the value, the higher the degree of specialization of the industry type in the region. The formula is as follows:

$$
Q=e_{K-A} / e_{K}
$$

where $Q$ is Location Quotient, $e_{K-A}$ is the ratio of the number of outlets of industry type $A$ in area $K$ to the total number of all outlets of industry type $A$ in the entire area, $e_{K}$ is the total number of outlets in area $K$ and the number of outlets in the entire area ratio.

\section{Analysis of the Spatial Pattern of Mianyang Commerce}

\subsection{Overall Distribution Characteristics of Commercial Outlets}

Using the Average Nearest Neighbor Distance module in ArcGIS to analyze commercial outlets, it was found that the NNI of the commercial outlets was 0.186980 , and the Z-score value was -340.706350 . Passing the test at a significance level of $1 \%$, it showed that the commercial outlets in the downtown area of Mianyang Agglomeration characteristics are very obvious. Using Kernel Density to analyze the distribution pattern of commercial outlets (Figure 3), and it can be seen that: 1) Through the analysis, the identified commercial core cluster area is from Nanhe Road to Linyuan Road. The representative commercial shopping centers are Kaide shopping center, Changhong shopping center and Macy shopping center. This area has a large population density and high retail consumption, and the commercial outlets are large in quantity and strong in agglomeration. Relying on convenient transportation and perfect commercial infrastructure, the level of commercial development in this area is relatively high. 2) The distribution of commercial outlets has gradually formed a polycentric hierarchical structure system. Specifically, the spatial distribution of commercial outlets has initially formed multiple agglomeration centers, and the distribution density generally shows a gradual decrease from the central area to the peripheral development areas. 3) High-density commercial outlets at the river confluence are connected into pieces, forming a "Y"-like distribution overall. Commercial outlets are densely distributed along the north side of the Anchang River under the influence of Wanda shopping center and the railway station. Obvious 


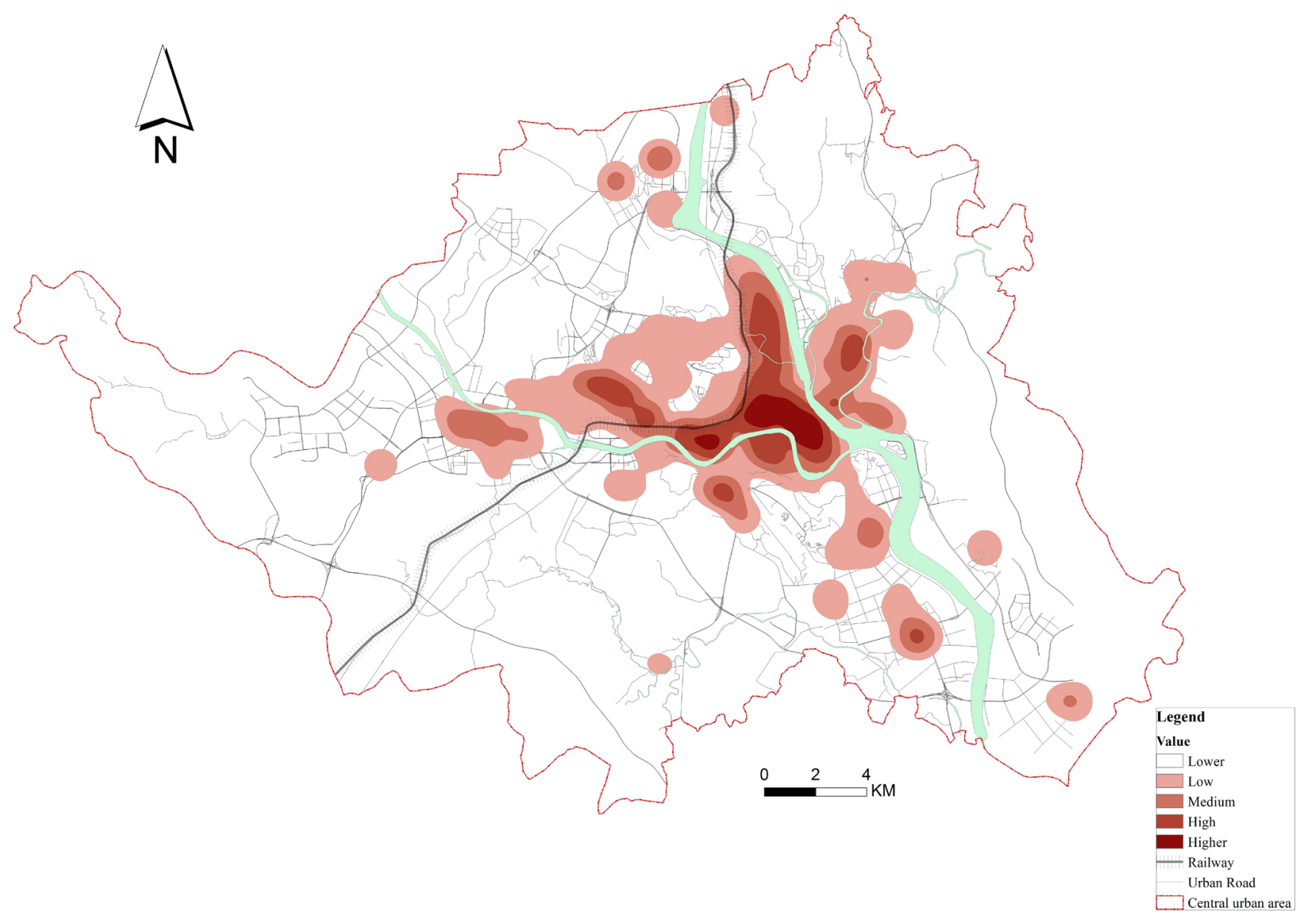

Figure 3. Kernel density of commercial outlets in Mianyang.

differences, showing the characteristics of sparse distribution of commercial outlets on the west side of the railway. 4) The secondary commercial clusters rely on convenient transportation, and the commercial outlets are also densely distributed around the traffic arterial roads and gradually decrease in number as the distance increases, while the urban fringe area is far from the city center, forming a relatively small-scale cluster "Island". In general, a more reasonable commercial-grade scale structure system has been formed in the downtown area of Mianyang as a whole.

\subsection{Agglomeration Characteristics of Commercial Outlets in the Block}

Based on the grid units divided by the city's main roads, the Global Moran's I is used to analyze the agglomeration characteristics of the spatial distribution of commercial outlets. After calculation, the Moran's I index of the spatial distribution of commercial outlets in the downtown area of Mianyang is 0.207039 . Passing the test at a significance level of 0.01 , it shows that there is a significant spatial positive correlation in its spatial distribution. In order to further verify the analysis results, the local Getis-Ord $G_{i}^{*}$ index is used to analyze the commercial hot spot area with the block as the unit (Figure 4). The results show that the 


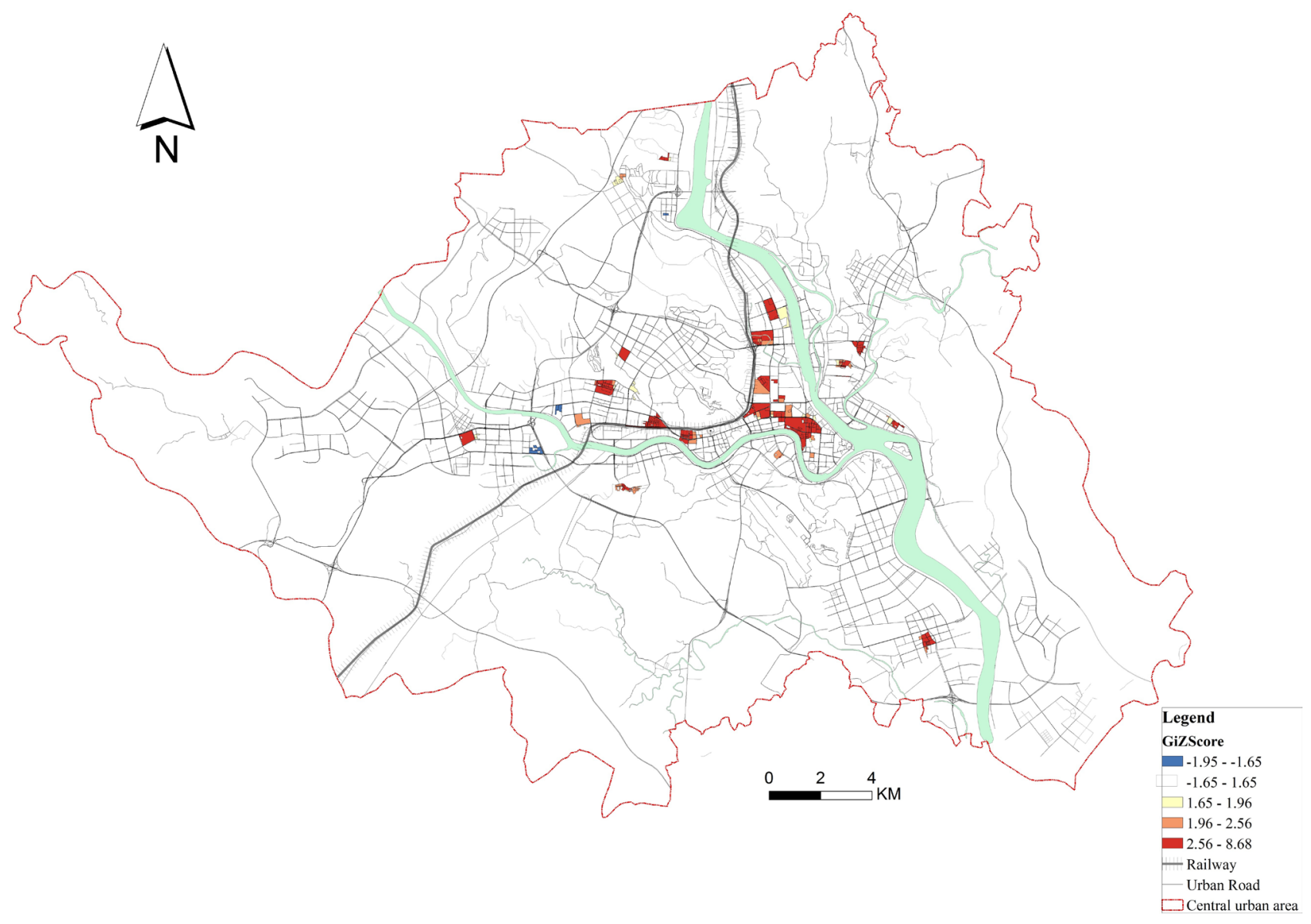

Figure 4. $G_{i}^{*}$ map of commercial outlets in Mianyang.

distribution of commercial outlets based on road grid units has significant hotspot clusters as a whole. The characteristics of the cold spot area are not significant. In the first category, with a $99 \%$ confidence level, the hotspots with a $\mathrm{Z}$-score greater than 2.56 ( $\mathrm{P}$ value $<0.01$ ) for testing are the Fule Road, Anchang Road, Jianmen Road, Yingbin Road, Gaoshui North Street, Gaoping Road, Hehua East Street, Jinxing East Road, Huoju Street Shiqiaopu Road, Tangxun South Stree in Fucheng District, and Shenfu Street Youxian Road, Wuli Dui Road in Youxian District. It is shown that the commercial outlets in the above areas is most densely distributed and surrounded by other adjacent spaces with high network density, forming the most prominent hot-spot gathering area, which is the most active area of commercial activities in the Mianyang downtown. From the perspective of administrative division, the hot spot gathering area along the three rivers confluence to the east side of the railway in Fucheng District is concentrated and connected, while there are only small and relatively independent hot spot gathering areas in Youxian District. According to the guidance of Mianyang's master planning, Fucheng District assumes the responsibilities of a regional business, commerce, and tourism service center. Compared with Youxian District, commercial development is faster and the commercial center is more attractive. Therefore, the commercial hot spots gathering area in Youxian Dis- 
trict are mainly used as the center of the area to serve the surrounding residential groups, which has radiation effect in a certain range. In the second category, with $95 \%$ confidence, hotspots with a Z-score greater than $1.96(\mathrm{P}$ value $<0.05$ ) for testing are mainly distributed in Fucheng District. Although these areas have small-scale commercial centers, In terms of distribution, most of its blocks form relatively significant hotspots that are not surrounded by other neighboring high-density commercial network blocks. The third category is the area where the $\mathrm{Z}$-score used for the test is between -1.65 - 1.65. The spatial autocorrelation is weak, and the distribution of commercial outlets in the neighborhood is random.

\section{Industry Distribution of Commercial Space in Mianyang}

\subsection{Spatial Aggregation Degree}

According to the calculation of Average Nearest Neighbor (Table 2), the degree of spatial aggregation of various commercial outlets is obtained. From the obtained $\mathrm{I}_{\mathrm{NN}}$, the strongest degree of aggregation is textile, clothing and daily necessities, with an $\mathrm{I}_{\mathrm{NN}}$ of 0.150381 , followed by household building materials and catering commercial outlets. The $\mathrm{I}_{\mathrm{NN}}$ of automobile service, recreational and sports supplies and equipment, food and tobacco, medicine and medical equipment, and household appliances and electronic products commercial outlets are distributed within the range of 0.21 to 0.24 , showing an average degree of aggregation, while the distribution of commercial outlets for leisure and entertainment and comprehensive retail is relatively dispersed. The different nature of commercial formats leads to different spatial layout patterns. Textile, clothing and daily necessities commercial outlets have strong leasing capabilities. The clusters of clothing stores tend to produce the largest agglomeration economic benefits and enhance the overall consumption vitality of the area. Generally, the degree of agglomeration is high. Most of the consumer groups in the home

Table 2. Statistical results of average nearest neighbor analysis.

\begin{tabular}{ccc}
\hline Commercial outlet type & $\mathrm{I}_{\mathrm{NN}}$ & $Z$-score \\
\hline Textiles, clothing and daily necessities & 0.150381 & -103.986275 \\
Hardware, home and interior decoration materials & 0.177014 & -116.273526 \\
Catering service & 0.185837 & -161.932906 \\
Automobile, motorcycle fuel and spare parts & 0.218013 & -44.829956 \\
Cultural, sporting goods and equipment & 0.223604 & -39.38147 \\
Food, beverage and tobacco products & 0.235346 & -66.378011 \\
Medicine and medical equipment & 0.237977 & -67.090665 \\
Household appliance and electronic product & 0.238885 & -49.484826 \\
Comprehensive Retail & 0.293587 & -68.789633 \\
Leisure and recreation & 0.299603 & -44.419508
\end{tabular}


building materials market and restaurants have a clear purpose, and the centralized layout can meet consumer purchase needs. In order to meet the trajectory of residents' activities and flexible operation, the commercial outlets of automobile services, recreational and sports products and equipment, food and tobacco, medicine and medical equipment, and household appliances and electronic products have a general degree of agglomeration. The layout of leisure, entertainment and comprehensive retail commercial outlets is affected by population distribution, service radius, traffic conditions and other factors, and generally the degree of agglomeration is relatively weak.

\subsection{Spatial Distribution Characteristics of "Center-Periphery"}

To better study the "Central-Peripheral" differences in the number and density distribution of commercial space industries, taking Mianyang Railway Station as the center of the circle and every $2 \mathrm{~km}$ as the buffer zone kernel density analysis of commercial outlets in various industries. The results can be seen (Figure 5): 1) In all industries, except for the automobile and motorcycle industries, the other six categories of industries have formed significant density distribution centers, while the density centers of comprehensive retail, medicine and medical equipment commercial outlets are relatively large. 2) In terms of the distribution pattern of various industries, the comprehensive retail, medical, catering and entertainment industries have formed significant density centers in multiple circles, and the size of each density center is relatively large, belonging to the distribution pattern of "great dispersion and great agglomeration". Culture, sports goods and equipment, household appliances, food and beverage, hardware furniture and interior decoration materials, automobile, motorcycle fuel and spare parts, the industry shows the "large dispersion, small agglomeration" mode; The textile, clothing and daily necessities industries show a "small dispersion, small agglomeration" pattern. 3) From the perspective of the circle distribution of each density center, in the core circle of $6 \mathrm{~km}$, cultural and sports goods and equipment, textile and clothing, food and beverage, hardware, furniture and interior decoration materials, household appliances and electronic products industry high density agglomeration, indicating that affected by the high density population distribution and location advantages in the central area, its location selection is more concentric. The automobile, motorcycle fuel and spare parts industries are more inclined to form high-density clusters in urban fringe areas, and their spatial distribution is highly eccentric. Because of its need for large-scale sites, tends to be located in the peripheral areas of the city, which are close to the main traffic routes and low rent. On the whole, the spatial differentiation of commercial outlets is significant, and the difference of industry attributes has a significant impact on the location selection of commercial outlets.

According to the statistics of the distribution of commercial outlets in each circle (Figure 6), it can be seen that the commercial outlets in Mianyang are mainly distributed within the $10 \mathrm{~km}$ circle with the railway station as the center, 

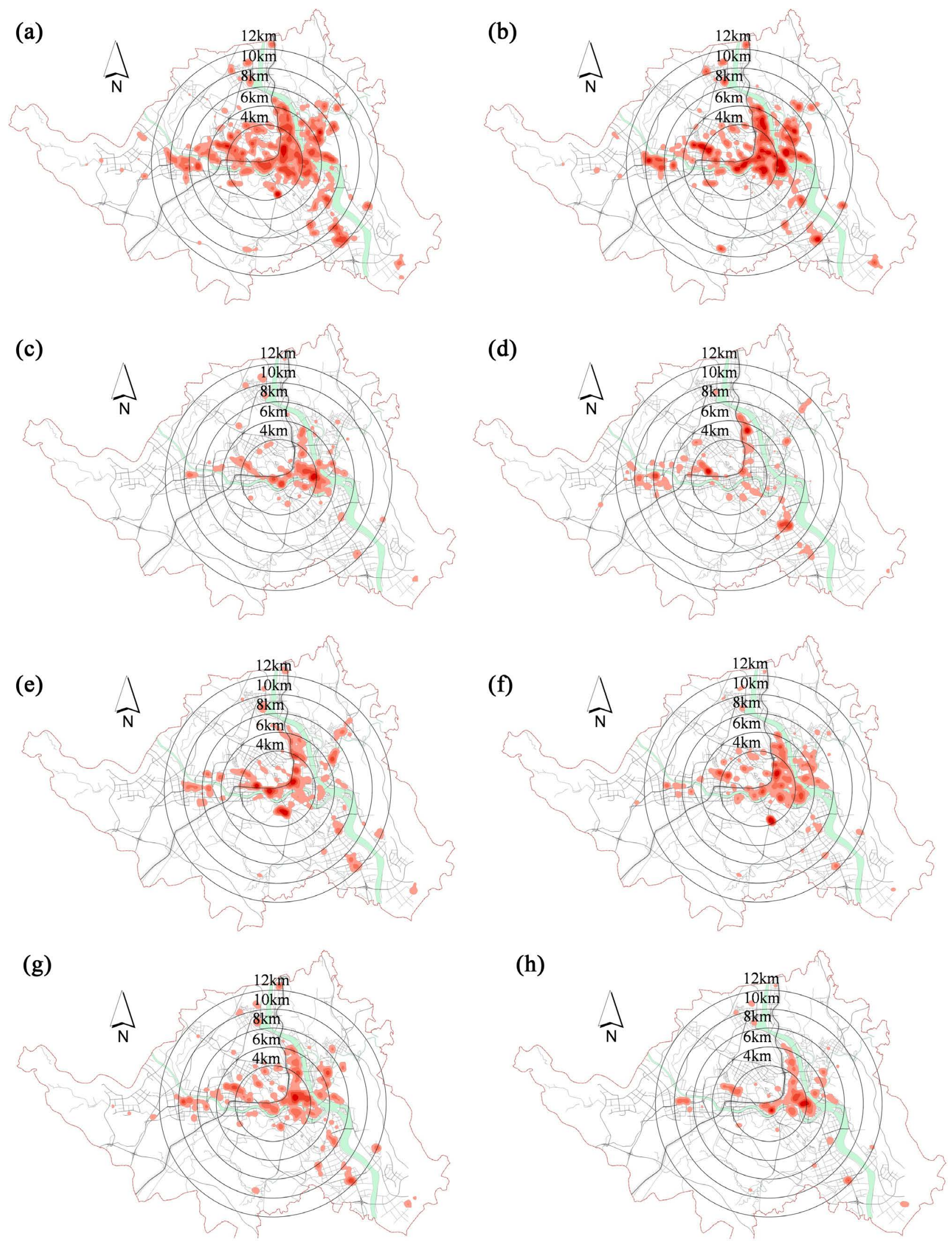
(i)

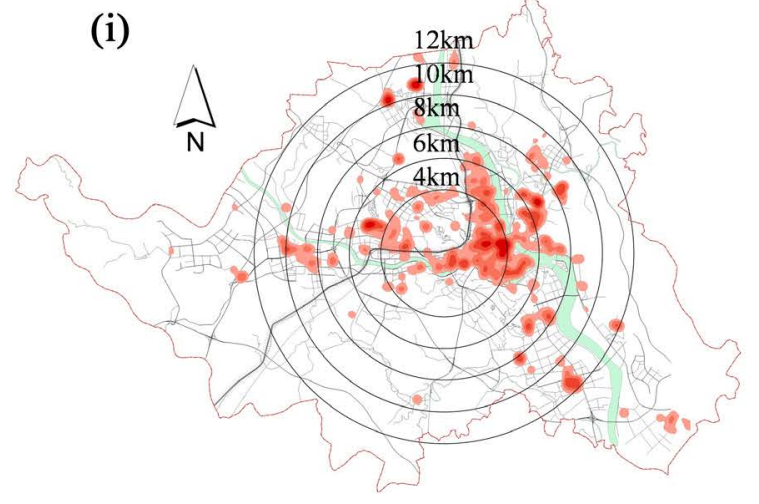

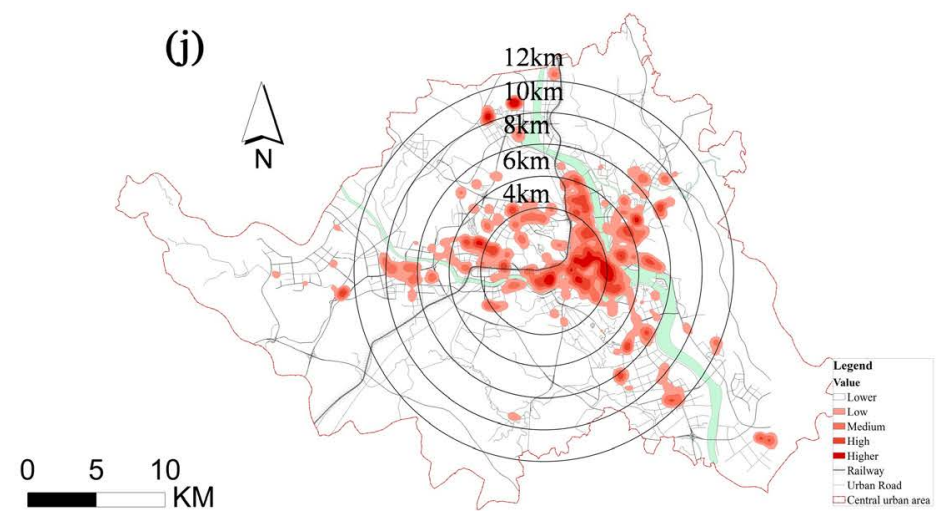

Figure 5. Kernel density of different industries in Mianyang. (a) Comprehensive Retail; (b) Medicine and medical equipment; (c) Cultural, sporting goods and equipment; (d) Automobile, motorcycle fuel and spare parts; (e) Hardware, home and interior decoration materials; (f) Food, beverage and tobacco products; (g) Household appliance and electronic product; (h) Textiles, clothing and daily necessities; (i) Leisure and recreation; (j) Catering service.

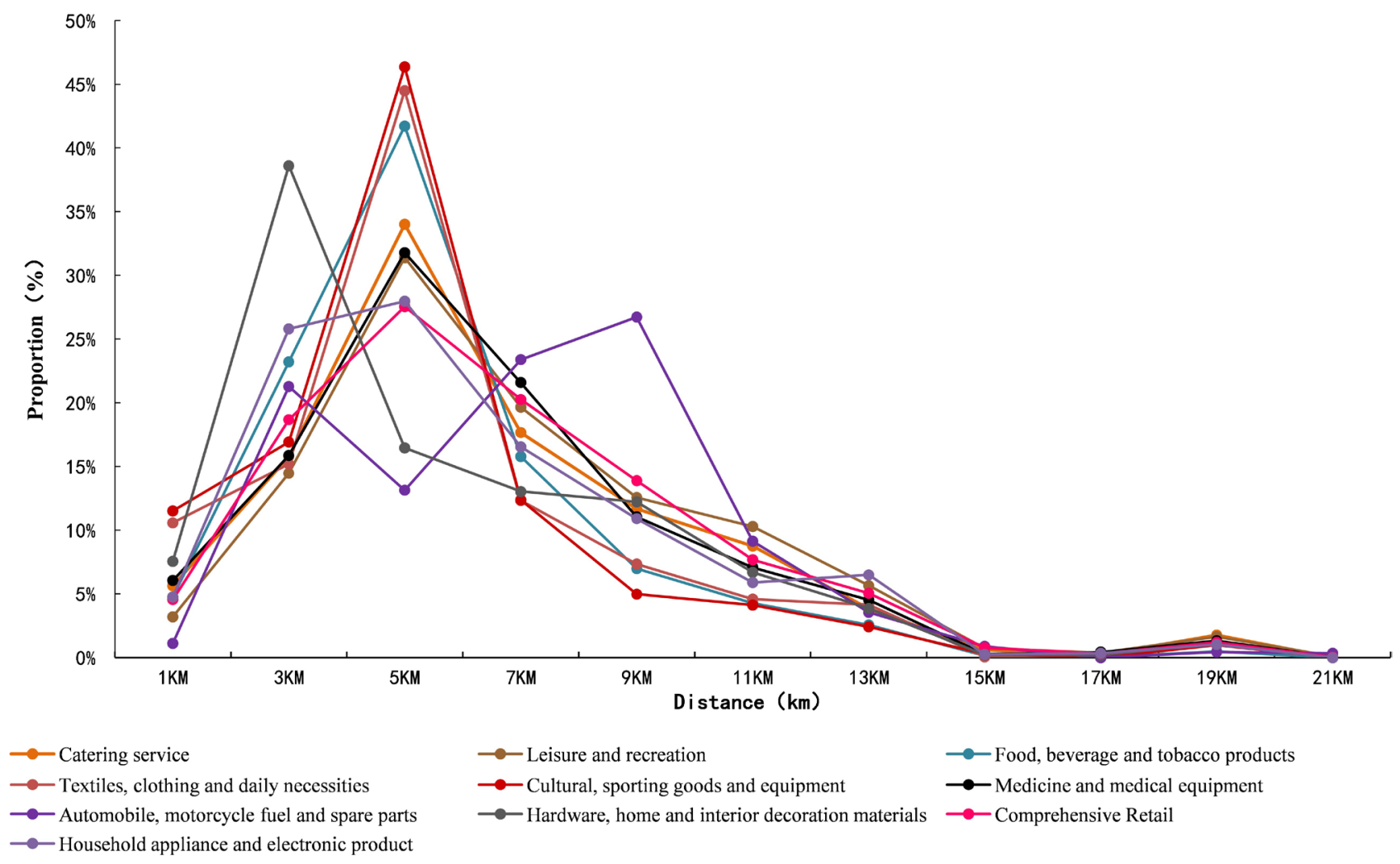

Figure 6. Circle density of industrial distribution in Mianyang.

and various commercial activities decreasing from the center to the periphery. From the perspective of the number of circles in each industry, within the range of $2-4 \mathrm{~km}$, the proportion of the distribution of the hardware, home and interior decoration materials industry reached the largest. Within the range of $4-6$ $\mathrm{km}$, the distribution of culture, sports goods and equipment, textile, clothing and daily necessities, and food, beverage, tobacco products commercial outlets are relatively concentrated. Within the range of 6 to $8 \mathrm{~km}$, the number of commercial outlets in various industries is evenly distributed. Within the range of 8 to 10 
$\mathrm{km}$, the number of commercial outlets in the automotive, motorcycle fuel, and spare parts industries reaches the maximum.

\subsection{Characteristics of Multi-Scale Spatial Agglomeration}

The calculation results of Ripley's $\mathrm{K}$ function show that within a $10 \mathrm{~km}$ observation range, the distribution of commercial outlets of automobiles, motorcycle fuels, and spare parts shows a "double peak" feature, while the distribution of commercial outlets in other industries shows a "single peak" feature (Figure 7). From the distance of the peak, catering services, food and beverage, tobacco products, medical and medical equipment and comprehensive retail industries show the agglomeration characteristics in a large space, and the scale of location selection is large, with the peak value appearing at $5.3 \mathrm{~km}, 5.3 \mathrm{~km}, 5.2 \mathrm{~km}$ and $5.6 \mathrm{~km}$, respectively. The largest gathering radius of the textile and clothing and daily necessities industry, cultural and sporting goods and equipment industry, hardware furniture and interior decoration materials, leisure and entertainment, and household appliances and electronic products industries appears relatively small, which are $4.3 \mathrm{~km}, 4.6 \mathrm{~km}, 4.9 \mathrm{~km}, 4.9 \mathrm{~km}, 4.9 \mathrm{~km}$. The minimum distance of the peak value in the automobile and motorcycle fuel and spare parts industry is $1.8 \mathrm{~km}$ and the maximum distance is $6.2 \mathrm{~km}$, indicating that the scale range of its spatial location selection can be large or small. From the perspective of industry characteristics and distribution, the comprehensive industries that focus on basic social services, such as catering services, food and beverage, comprehensive retail, and pharmaceutical and medical industries, have relatively little influence from spatial location. In order to bring greater service coverage, they are dispersed in the core and fringe areas of the city. Some industries that have high requirements for location selection, such as textiles and clothing, culture and sports, are mostly distributed in urban business districts, and they tend to be located in core urban areas. Automobile, motorcycle fuel and spare parts, hardware, furniture and interior decoration materials, household appliances and electronic products industries due to the requirements of site size, tend to layout in the outer areas of the city. The service coverage of the leisure and entertainment industry is less than that of the comprehensive industry mainly based on basic social services. The "double peak" feature of the former Ripley's K function also further shows the difference between the two types of commercial outlets in the industry. Relatively speaking, the motorcycle fuel and spare parts industry has a smaller range of spatial scales and is more likely to form dense distribution.

\subsection{Characteristics of Specialized Functional Area}

The study selects the administrative division of Mianyang for the measurement of location entropy (Figure 8). Judging from the results of location entropy measurement (Figure 9), some industries have formed specialized functional clusters $(\mathrm{Q}>2)$ at the sub-district and town levels, and part of sub-districts and towns exhibit the characteristics of a single dominant industry cluster, such as 
pine street comprehensive retail industry, WuJia Town pharmaceutical and medical equipment industry, etc., while most of the streets is characterized by a multitude of industry relatively concentrated $(Q=1-2)$, and reached a certain degree of specialization, such as medicine and medical equipment and automobile, motorcycle fuel and spare parts industry in Gongqu sub-district. Generally
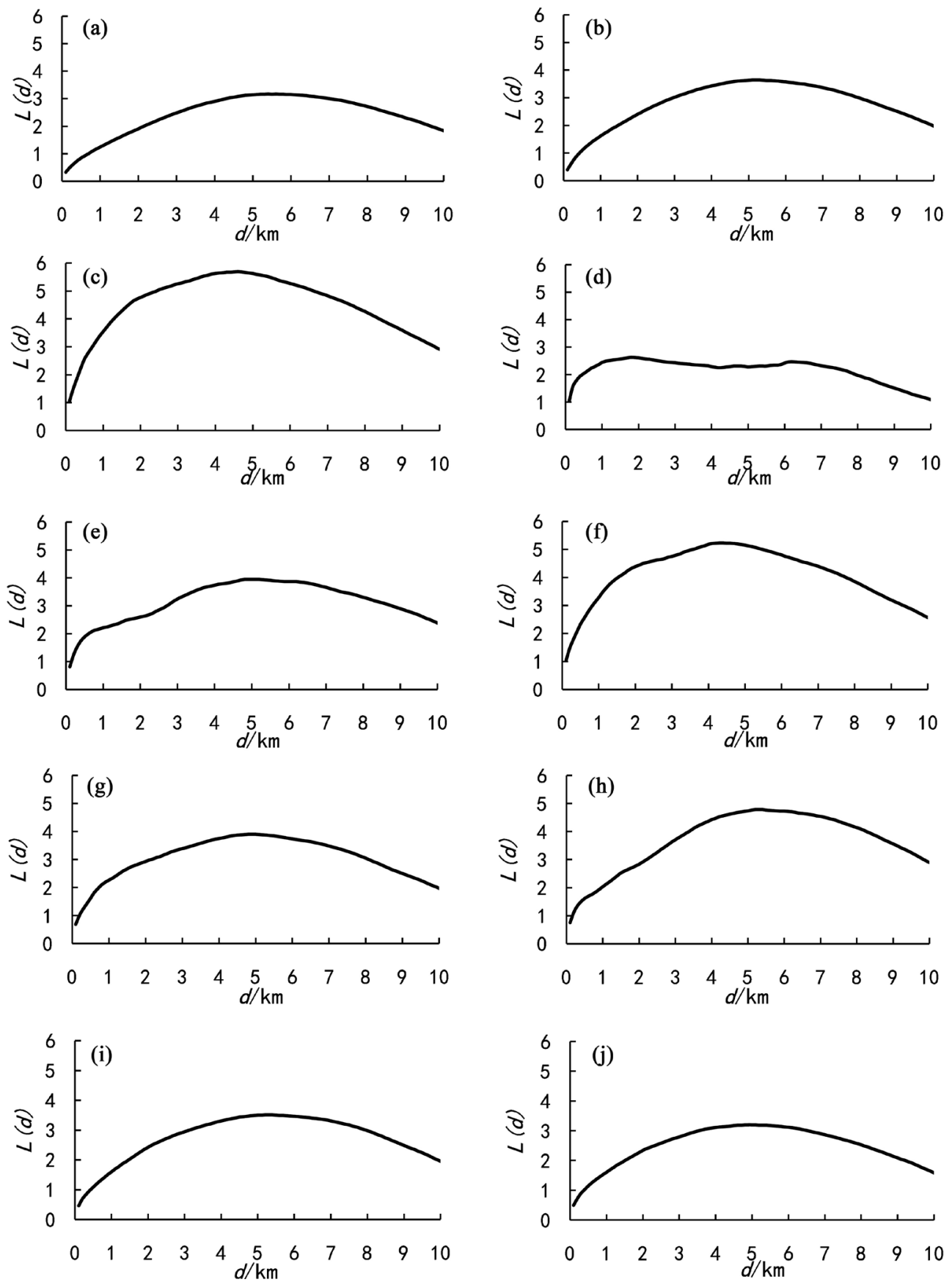

Figure 7. Results of Ripley's K function of industry. (a) Comprehensive Retail; (b) Medicine and medical equipment; (c) Cultural, sporting goods and equipment; (d) Automobile, motorcycle fuel and spare parts; (e) Hardware, home and interior decoration materials; (f) Textiles, clothing and daily necessities; (g) Household appliance and electronic product; (h) Food, beverage and tobacco products; (i) Catering service; (j) Leisure and recreation. 


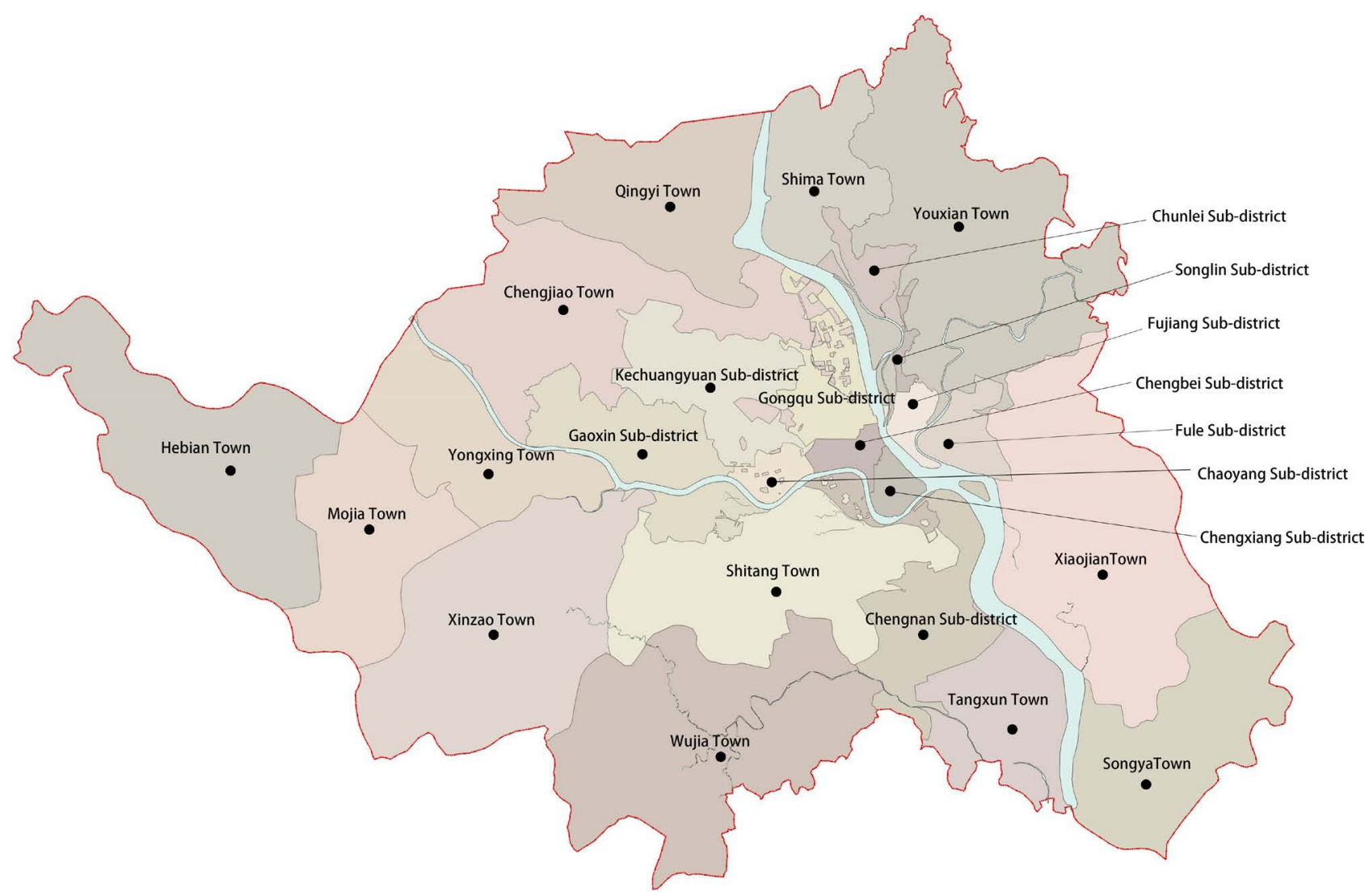

Figure 8. Administrative division map of downtown Mianyang.

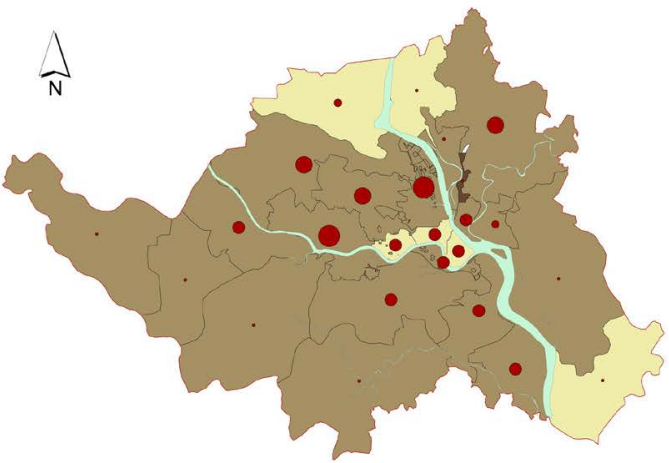

(a)

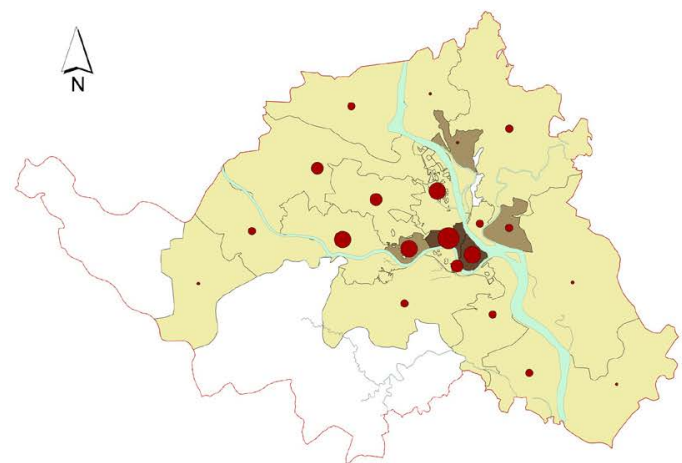

(c)

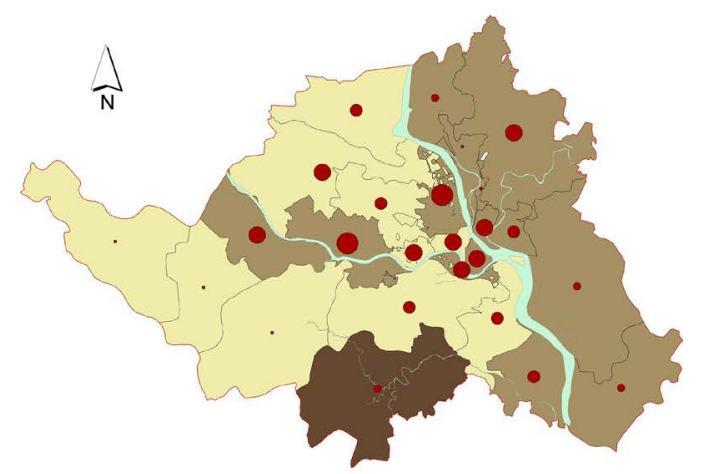

(b)

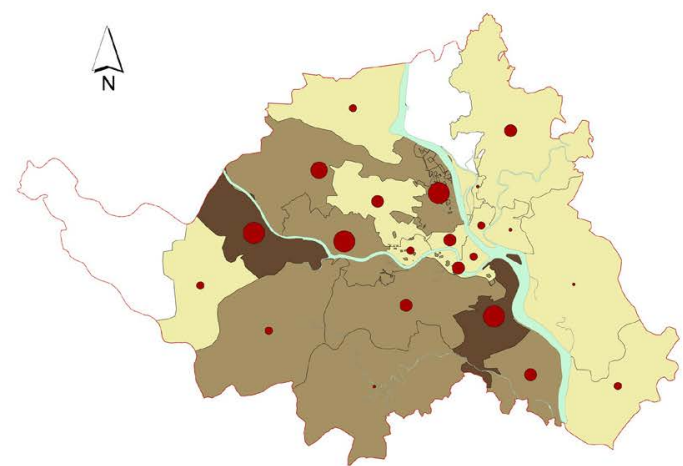

(d) 


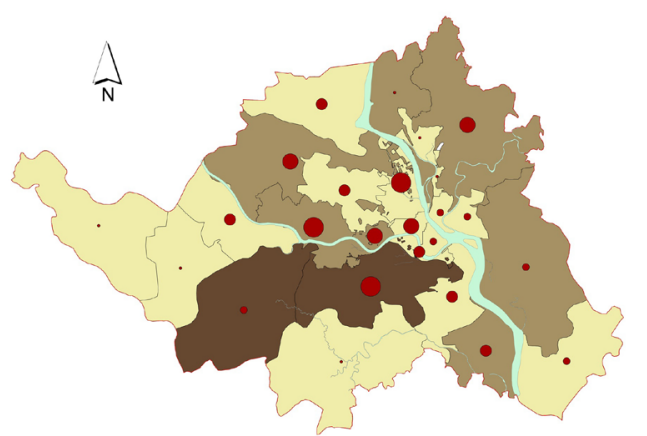

(e)

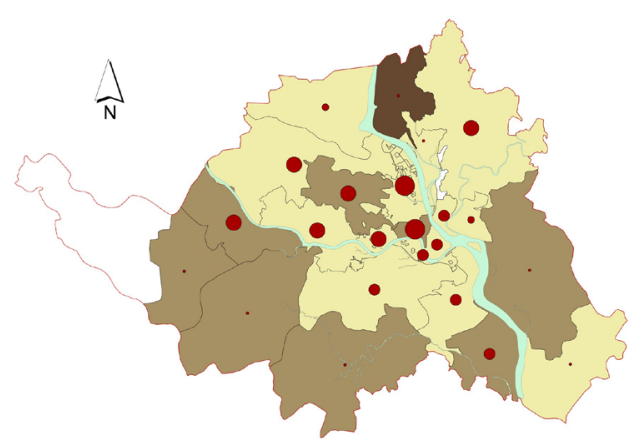

(g)

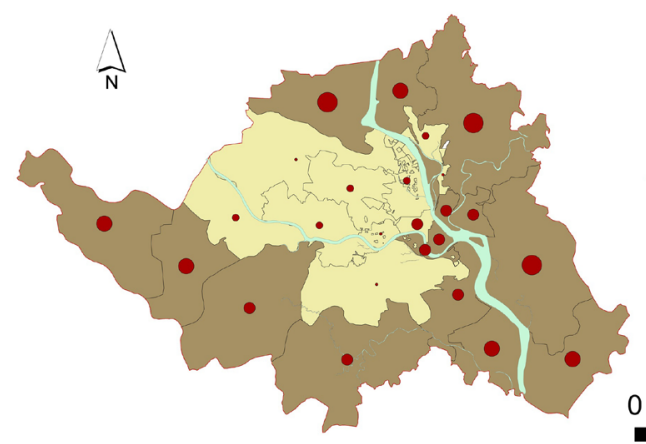

(i)

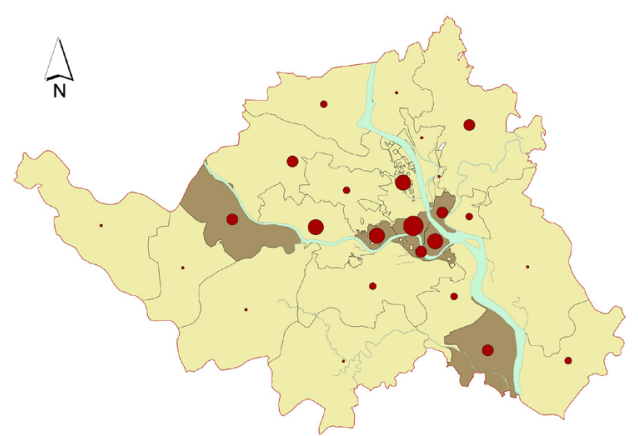

(f)

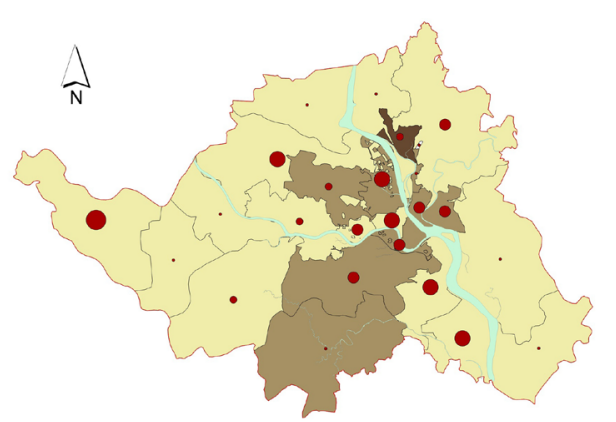

(h)

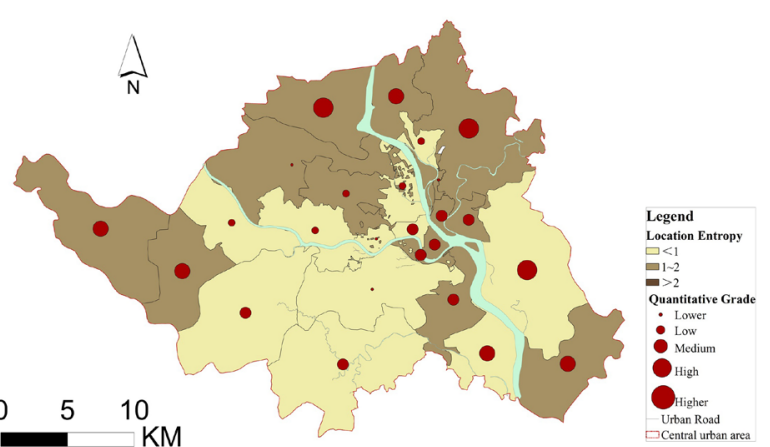

(j)

Figure 9. Distribution of location entropy and quantitative grade of commercial outlets at sub-district and town scale in Mianyang. (a) Distribution of location entropy and quantitative grade of comprehensive retail; (b) Distribution of location entropy and quantitative grade of Medicine and medical equipment; (c) Distribution of location entropy and quantitative grade of cultural, sporting goods and equipment; (d) Distribution of location entropy and quantitative grade of automobile, motorcycle fuel and spare parts; (e) Distribution of location entropy and quantitative grade of hardware, home and interior decoration materials; (f) Distribution of location entropy and quantitative grade of textiles, clothing and daily necessities; (g) Distribution of location entropy and quantitative grade of household appliance and electronic product; (h) Distribution of location entropy and quantitative grade of food, beverage and tobacco products; (i) Distribution of location entropy and quantitative grade of leisure and recreation; ( $j$ ) Distribution of location entropy and quantitative grade of catering service.

speaking, there is a great difference in the degree of industry specialization among sub-districts and towns. Mature sub-districts and towns show the characteristics of multi-advantage industry agglomeration, [16] but the degree of specialization is not high enough, such as Chaoyang and Gongqu sub-district. There are also a few fast-developing sub-districts and towns that exhibit the 
characteristics of multi-advantaged industries. For example, Qingyi town, relying on the surrounding colleges and universities, has rapidly developed catering services and leisure and entertainment industries, forming the characteristics of multi-advantage industries gathering. The sub-districts and towns with low development levels are generally less specialized in various industries. From the characteristics of specialized functional areas in various industries, comprehensive retail, automobile, motorcycle fuel and spare parts, hardware and home furnishing and decorative materials industries have formed multiple industrial function clusters, and the number of specialized functional areas in other industries is relatively small. From the perspective of the spatial layout of various industries, the medicine and medical equipment, household appliances and electronic products and the leisure and entertainment industries form the industry advantage zone in the peripheral sub-district and town of the city, while the cultural, sporting goods and equipment, textile, clothing and daily necessities industries are mostly concentrated in the downtown sub-district. Combined with the distribution of the number and grade of commercial outlets in the sub-district and town, these industries, while densely distributed in some blocks, also show the professional advantages of the industry, which is generally consistent with the characteristics of hot spots in the "center-periphery" of each industry. However, it is worth noting that all kinds of industries are densely distributed in the downtown sub-district and town of the city, forming relatively few specialized functional areas. On the contrary, the marginal sub-district and town of the city are more likely to form specialized advantageous areas of the industry due to the relatively small number of functional elements.

\section{Discussions}

In general, the research on the distribution of urban commercial outlets and industry clustering characteristics based on POI data makes the understanding of urban commercial space more refined. The identification of commercial centers and the analysis of industrial characteristics can help improve government departments' planning of urban commercial outlets and scientific analysis of business industry development. From the identification results of the commercial center, it reflects the system pattern of the existing commercial center in Mianyang, but some planned commercial centers are still not reflected, which indicates that the development of these commercial centers is not yet mature. At the same time, the formation of the multi-center pattern of commercial space shows that the external decentralization trend of commercial function elements is strengthened, and the traditional single-core agglomeration of urban service function is transitioning to multi-core and multi-level agglomeration, which also shows that the policy effect of government guidance to dredge the service function in the central area has been reflected. The analysis of the dominance of the commercial industry can accurately identify the areas with significant industry advantages and high scale and quantity, which is helpful to deepen the under- 
standing of the specialized functional agglomeration area of the industry. However, due to the lack of POI data attribute information, such as lack of creation time, outlet size, etc., it is difficult to discuss the formation mechanism of the commercial space pattern. In the future, we should further explore the causality behind the spatial pattern of urban commercial industry in combination with the "small data" of the traditional survey. In addition, although the paper analyzes and obtains the spatial scale range of the maximum agglomeration in each commercial industry, whether it is really the scope of producing the best agglomeration benefit, or whether it can guide the layout of all kinds of commercial industries based on this scope, still needs to be deeply explored.

\section{Conclusions}

The spatial concentration and dispersion of commercial outlets is an important manifestation of retail business activities. Commercial space research in the traditional format perspective focuses on the distribution of stores with specific business methods, product structures and service functions. It focuses more on the structural characteristics of retail stores. However, due to the differences in industry attributes, there are still some deficiencies in the research of business format perspectives. Based on the commercial industry division, using POI geospatial data, the paper analyzes the commercial space pattern of Mianyang's downtown area, and explores the spatial distribution and agglomeration characteristics of various industries. Research indicates:

1) Urban commercial spatial distribution is characterized by significant agglomeration and has shown a polycentric distribution pattern. On the whole, it presents a "Y-type" agglomeration with the commercial area from Nanhe road to Linyuan road as the core, the commercial distribution spatial pattern with the area around Wanda shopping center and railway station, the peripheral area radiated by Tanghong international shopping center as the sub-center, and several secondary centers gradually formed in the urban fringe. The cluster area of road grid of commercial network is consistent with the distribution of identified commercial hot spots, but the influence of different commercial centers on adjacent grid is different. In addition, the hierarchical scale structure of the commercial center system is reasonable, with more primary and secondary centers and fewer secondary centers, indicating that the polycentric pattern of commercial centers has been formed.

2) The "center-periphery" of urban commercial space is clearly differentiated from the industry perspective, and the multi-scale spatial agglomeration performance of different industries is different. The characteristics of the circle show that various types of commercial activities in the city are mainly distributed within a distance of $6 \mathrm{~km}$. The industries of textile, clothing and daily necessities, food, beverage and tobacco products tend to be densely distributed in the core circle, while the industries of automobile, motorcycle fuel and spare parts, hardware, furniture and interior decoration materials tend to form high-density 
clusters in the peripheral areas, and different retail industries show different spatial distribution patterns. The industries with a wide range of spatial scales include comprehensive retail, food, beverage and tobacco products, household appliances and electronic products, medicine and medical equipment, while textile, clothing and daily necessities, culture, sporting goods and equipment, hardware furniture and automobile and motorcycle industries have a small range of spatial scales.

3) There are significant differences in specialized functional area from an industry perspective. Some commercial industries have formed certain specialized functional areas. The mature sub-districts and towns show the characteristics of multi-advantaged industry clusters, but the overall degree of specialization is not high. The sub-district and town in fast-growing streets also have a small number of block functions that show multi-industry clusters characteristics. The sub-districts and towns with low levels of development generally have low levels of specialization in various industries. From the comprehensive view of the degree of industry dominance and the number of outlets, the sub-districts and towns in the central area of the city have a significant industry advantage while showing a high number of level distribution. On the contrary, the sub-district and town in the edge areas are more likely to form smaller-scale industry advantage zones.

\section{Acknowledgements}

I would like to express my gratitude to all those who have helped me during the writing of this thesis. I gratefully acknowledge the help of my supervisor Professor Li Changqi. My gratitude also extends to my family who have been assisting, supporting and caring for me all of my life.

\section{Conflicts of Interest}

The authors declare no conflicts of interest regarding the publication of this paper.

\section{References}

[1] Christaller, W. and Baskin, C.W. (1966) Central Places in Southern Germany. Prentice-Hall, Englewood Cliffs, NJ.

[2] Berry, B.J.L. and Parr, J.B. (1988) Market Centers and Retail Location: Theory and Applications. Prentice Hall, Englewood Cliffs, NJ.

[3] Huff, D.L. (1964) Defining and Estimating a Trading Area. The Journal of Marketing, 28, 34-38. https://doi.org/10.1177/002224296402800307

[4] Bourne, L.S. (1979) Systems of Cities: Readings on Structure, Growth, and Policy. Oxford University Press, New York.

[5] Brotchie, J.F. (1991) Cities of the 21st Century: New Technologies and Spatial Systems, Melbourne, Australia.

[6] Wang, D. and Zhang, J.Q. (2001) The Analysis of Consumer Trip Characteristics and Spatial Structure of Commercial Facilities in Shanghai. City Planning Review, 
No. 10, 6-14.

[7] Xu, X.Q., Zhou, S.H. and Lin, G. (2002) The Locational Analysis of Guangzhou's Large Retail Emporia. City Planning Review, No. 7, 23-28.

[8] Zhou, S.H., Lin, G. and Yan, X.P. (2008) The Relationship among Consumer's Travel Behavior, Urban Commercial and Residential Spatial Structure in Guangzhou, China. Acta Geographica Sinica, No. 4, 395-404.

[9] Chai, Y.W., Weng, G.L. and Shen, J. (2008) A Study on Commercial Structure of Shanghai Based on Residents' Shopping Behavior. Geographical Research, No. 4, 897-906.

[10] Zhou, S.H., Hao, X.H. and Liu, L. (2014) Validation of Spatial Decay Law Caused by Urban Commercial Center's Mutual Attraction in Polycentric City: Spatio-Temporal Data Mining of Floating Cars' GPS Data in Shenzhen. Acta Geographica Sinica, 69, 1810-1820.

[11] Wang, D., Wang, C., Xie, D.C., et al. (2015) Comparison of Retail Trade Areas of Retail Centers with Different Hierarchical Levels: A Case Study of East Nanjing Road, Wujiaochang, Anshan Road in Shanghai. Urban Planning Forum, No. 3, 50-60.

[12] Hu, Q.W., Wang, M. and Li, Q.Q. (2014) Urban Hotspot and Commercial Area Exploration with Check-in Data. Acta Geodaetica et Cartographica Sinica, 43, 314-321.

[13] Chen, W.S., Liu, L. and Liang, Y.T. (2016) Retail Center Recognition and Spatial Aggregating Feature Analysis of Retail Formats in Guangzhou Based on POI Data. Geographical Research, 35, 703-716.

[14] Xu, D., Huang, Z.F., Lu, L., et al. (2018) Research on Spatial Characteristics of Urban Leisure Tourism Based on POI Mining: A Case Study of Nanjing City. Geography and Geo-Information Science, No. 1, 59-64.

[15] Zhao, H.B., Yu, D.F., Miao, C.H., et al. (2018) The Location Distribution Characteristics and Influencing Factors of Cultural Facilities in Zhengzhou Based on POI Data. Scientia Geographica Sinica, No. 9, 1525-1534.

[16] Hao, F.L., Wang, S.J., Feng, Z.X., et al. (2018) Spatial Pattern and Its Industrial Distribution of Commercial Space in Changchun Based on POI Data. Geographical Research, No. 2, 366-378. 